\title{
AUTOMATIC EXTERNAL CARDIAC MASSAGE: A PORTABLE PNEUMATIC EXTERNAL CARDIAC COMPRESSION MACHINE
}

\author{
BY \\ R. A. BAILEY, N. L. BROWSE, AND V. J. KEATING \\ From the Professorial Surgical Unit, Westminster Medical School, London S.W.1 \\ Received October 10, 1963
}

Massage or manual compression of the heart is accepted as a useful procedure when heart action has ceased because of accident or temporarily disordered function. Experience in the operating theatre has shown that manual massage through the open chest should be maintained for over an hour before being abandoned, but the procedure is tiring, and the operator must be relieved at frequent intervals.

Because of the resistance of the chest wall in adults, the power required to produce effective compression of the heart through the unopened chest is far greater and is estimated at between a quarter and a half horsepower. This power output cannot be maintained for more than ten minutes by any one person. If it is accepted that external cardiac massage produces a limited but effective circulation and that one hour is the minimum period of treatment, it is obviously desirable that mechanical assistance should be available to take over after the initial emergency manual compression. The procedure lends itself to mechanical substitution and the more precise control available should extend its use and possibly reduce the visceral damage due to uncontrolled violent chest compression.

This paper describes a cardiac massage machine and reports a series of experiments on dogs whose hearts had been stopped and whose circulations were then maintained for prolonged periods by it. The apparatus is small, light, portable, and safe, and its action is easy to control. Compressed air or oxygen was considered the most suitable power source as it is convenient for artificial ventilation, and its use is understood by those concerned with the operation of resuscitation apparatus. Electric batteries have not been used because they cannot supply the large power demands of this type of apparatus and might be found to be discharged when required in emergency, especially if stored for prolonged periods in adverse conditions. Mains electric power is rarely available on an accident site and could be dangerous in some situations, and the electro-pneumatic valves available must be controlled by electronic circuits fed by dry batteries which offer another source of failure in an emergency.

The machine was accordingly designed so that the timing circuits and the chest compression ram were operated solely by compressed gas. The ram can apply any weight from a few pounds to over a hundred in variable steps by operation of a single control without stopping the machine. The pressure applied can be observed on a simple gauge and the exact degree of chest depression seen by the operator. The machine can stop at suitable intervals to allow inflation of the chest and, if necessary, it can carry this out automatically.

As the timing circuits controlling heart compression, rate, and the pause for lung inflation, can be set in advance, the machine is no more difficult to operate than any other mechanical resuscitation apparatus designed for use by semi-skilled persons.

Requests for reprints should be addressed to Mr. N. L. Browse, F.R.C.S., at the Westminster Hospital. 


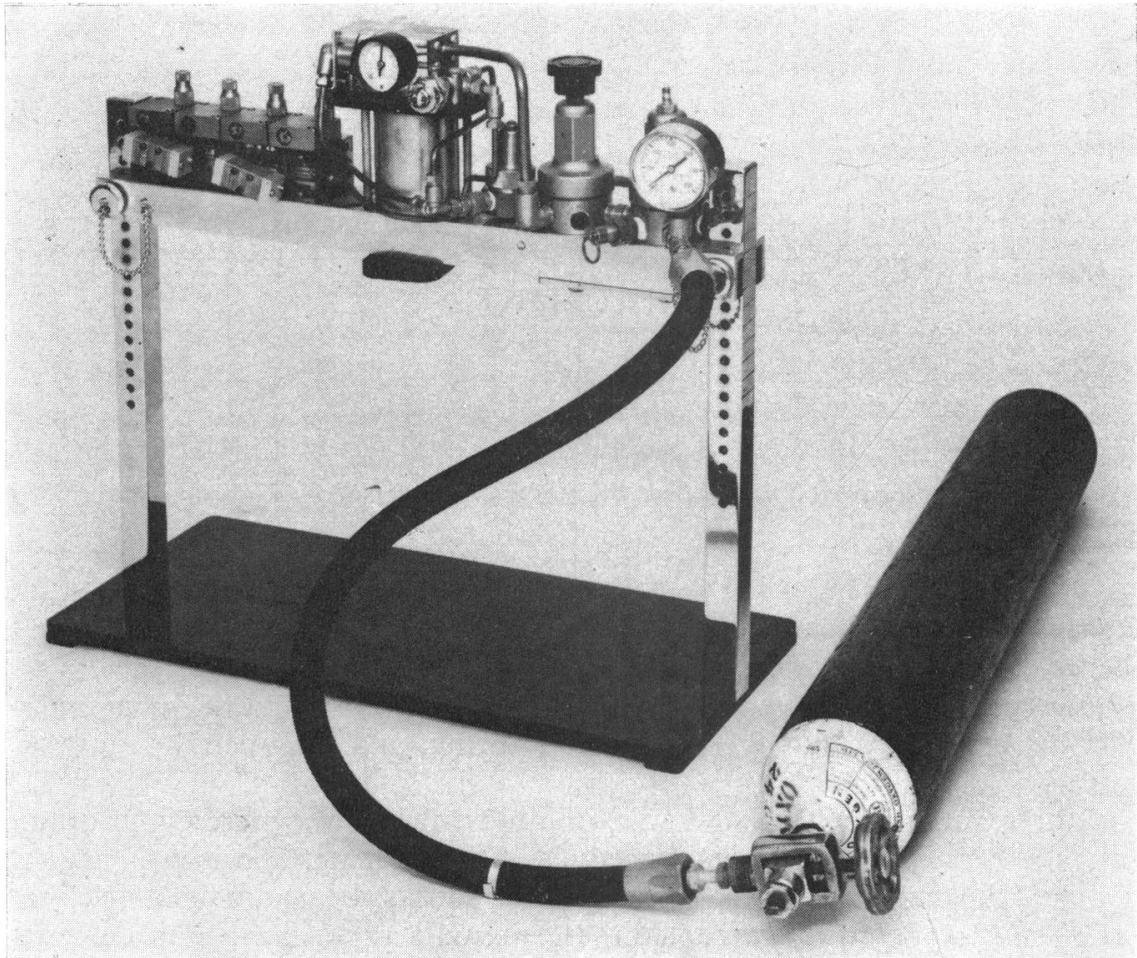

Fig. 1.-The cardiac massage unit. On the bridge piece from left to right can be seen: fingertip controls of rate of thrust, frequency and lengths of pause etc., thruster cylinder with gauge showing thrust applied, on-off switch, valve controlling thrust, reducing valve, and oxygen cylinder pressure gauge.

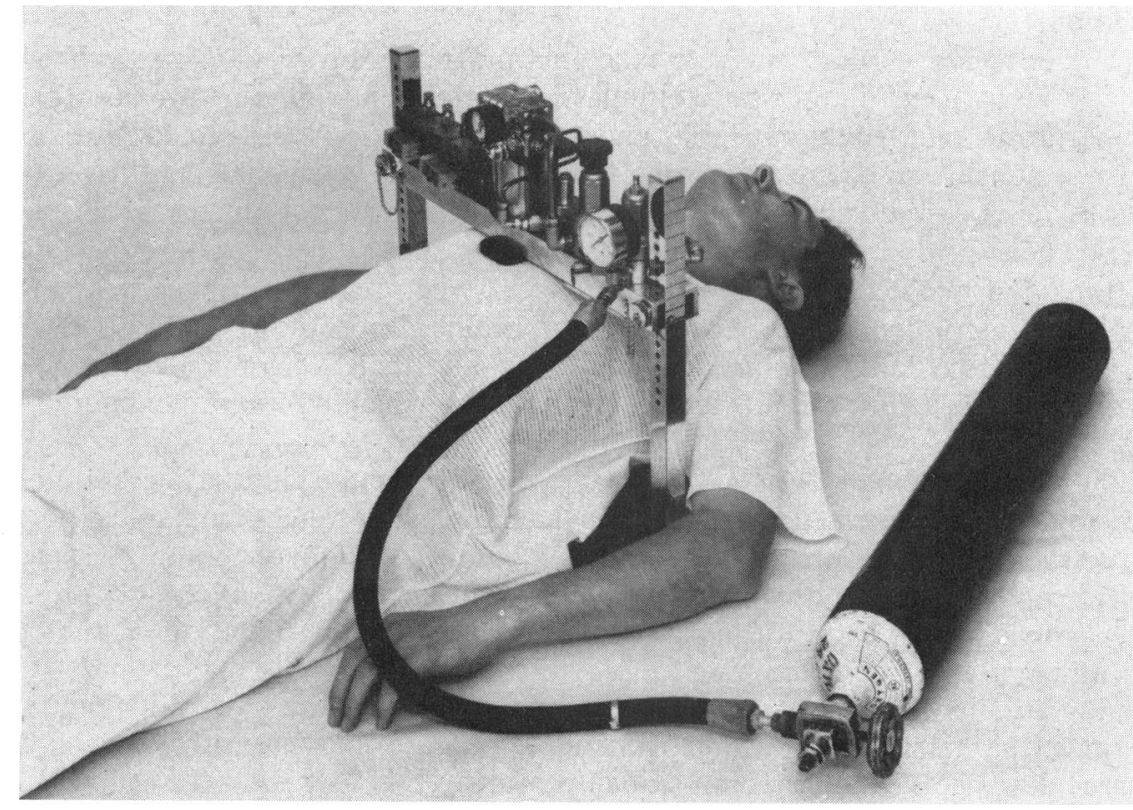

FIG. 2.-Patient in the cardiac massage unit. Note the compactness of the unit and the easy access to the patient especially the head and neck. 
The MAChine

The cardiac massage unit is a simple framework of a flat base, two uprights, and a bridge piece which carries the cylinder, or ram, and control mechanisms (Fig. 1). The bridge piece is adjustable for height by means of quick release pins which are located in a series of holes in the uprights. One upright is fixed to the base; the other is removable.

To place the machine around the patient's chest (Fig. 2), the base with its attached upright is slid under the patient; the other upright is placed in its location groove in the base; the bridge piece is lowered between the uprights until the pad is resting on the lower third of the sternum; and the two fixing pins are inserted. This procedure takes 15 seconds. After connecting to an oxygen bottle, the operator has only to switch on, increase the adjustable pressure regulator to give the required depression of the sternum, and the machine will then cycle automatically.

The following control facilities are incorporated; they have been used for the experimental and development work but would be pre-set on any machine intended solely for clinical use, leaving the machine to be operated by a single control.

(1) Duration of the downstroke of the ram.

(2) Duration of the upstroke of the ram.

(3) Length of the working period during which the ram is operating at the frequency determined by the setting of controls 1 and 2.

(4) The duration and frequency of the pause when the ram is static, to allow inflation of the lungs.

The ram is a single acting cylinder with a special P.T.F.E. (polytetrafluorethylene, "fluon") seal, which under normal usage will require no lubrication. The maximum movement of the pressure pad is $3 \mathrm{in}$. $(7 \cdot 7 \mathrm{~cm}$.). The rate of the ram can be varied from 5-120 thrusts per minute, and the downstroke can be made to occupy from one-third to two-thirds of a single cycle. The period of the pause can be from $0-15$ sec., and it can be inserted between any number of thrusts from 2-20. The oxygen which has activated the ram is exhausted to atmosphere via a valve on the top of the cylinder. It may be collected and fed to a face mask for use when inflating the lungs. The unit can be adapted to inflate the lungs automatically during the pause, thus giving mechanical artificial respiration as well as cardiac massage.

A standard 24 cubic foot oxygen cylinder will provide sufficient gas for 30 minutes' massage of 60 thrusts per minute of $90 \mathrm{lb}$. (41 kg.) thrust. The machine is truly portable, weighing only $22 \mathrm{lb}$. $(10 \mathrm{~kg}$.).

\section{EXPERIMENTAL STUDIES}

Two problems arise when one tries to study external cardiac massage. First, it is difficult to find an animal with a thoracic cage sufficiently similar to man for it to be acceptable to transfer conclusions from one to the other. Secondly, the measurement of blood flow, rather than blood pressure, is extremely difficult because the rate of flow that external massage produces is so low.

In this study we have used mongrel dogs. They have been of all shapes and sizes and we do not claim that their chests have been in any way similar to that of man. The first series of experiments was performed after "death," and no attempt was made to obtain survival. We have just begun survival experiments, and the first of these is reported.

Ancesthesia and the Arrest. The dogs were anæsthetized with intravenous pentobarbitone sodium ("nembutal"). Cardiac arrest was obtained by the intravenous injection of potassium chloride, 10-30 mEq. In two cases we stopped the heart with acetylcholine and in one case with a very large dose of pentobarbitone sodium.

Measurement Techniques. The arterial pressure was measured with a mercury manometer that wrote onto a kymograph. The tip of the arterial catheter was placed in the external iliac artery via the femoral artery. Venous pressures were measured and recorded in the same way: the tip of the venous catheter was placed in either the thoracic vena cava, the abdominal vena cava, or the femoral vein. One attempt was made to measure the cardiac output by a dye dilution technique using a whole blood cuvette. Circulation times were measured by timing the period between an intravenous injection of methylene blue and its appearance at a site of repeated arterial sampling. Oxygen saturations were measured with the Kipp hæmoreflector.

Position in the Machine. In the first few experiments, the dogs were put into the machine on their backs with the chest piece of the ram on their sternums. This failed to produce a blood pres- 


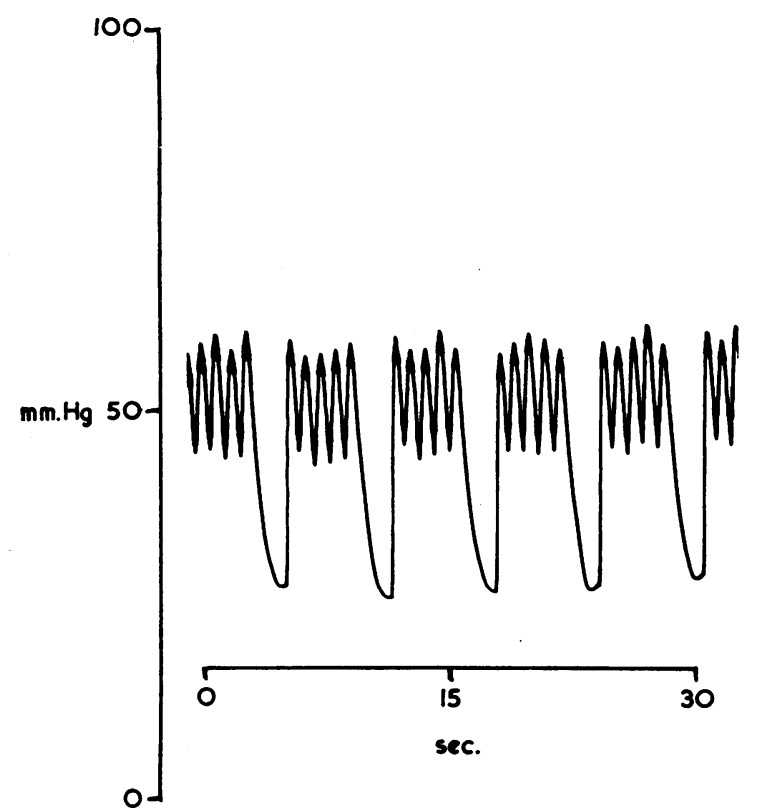

FIG. 3.-Typical arterial blood pressure trace during massage. Note pressure of $25 \mathrm{~mm}$. Hg even after a two-second pause. sure greater than $20 \mathrm{~mm}$. $\mathrm{Hg}$, so we turned the animals onto their sides and compressed the chest laterally. This is the way one applies manual external cardiac massage to dogs, and it was also much more effective with the machine.

All the figures given are from lateral cardiac massage, and this further invalidates any attempt to transfer results on the dog to results on man.

The Abdomen. We noticed in the early experiments that compression of the chest caused distension of the abdomen. At the same time the blood pressures that we were recording were low, $20-30 \mathrm{~mm}$. $\mathrm{Hg}$. We therefore strapped the abdomen from xiphisternum to pubis with non-stretch strapping to stop the distension: this immediately raised the blood pressure. All the figures given are from dogs with their abdomens strapped. At no time did we compress the abdomen, intermittently, or continuously, for it has been reported that this causes rupture of the liver (Birch et al., 1962).

The Arterial Blood Pressure. The maximum systolic blood pressure obtained in the 17 dogs studied ranged between 40 and $80 \mathrm{~mm}$. $\mathrm{Hg}$ with a mean of $55 \mathrm{~mm} . \mathrm{Hg}$ : this pressure rapidly dropped to zero when massage was stopped, but provided the pause was not too long it returned to its original level when massage was recommenced (Fig. 3).

The diastolic pressure at 60 thrusts a minute was $20 \mathrm{~mm}$. $\mathrm{Hg}$ below the systolic.

The Rate of Compression once it was above 40 compressions per minute did not affect the systolic pressure. In the upstroke phase the pressure dropped but returned to the systolic level as soon as compression was reapplied. Therefore, although the rate of compression had only a slight effect on
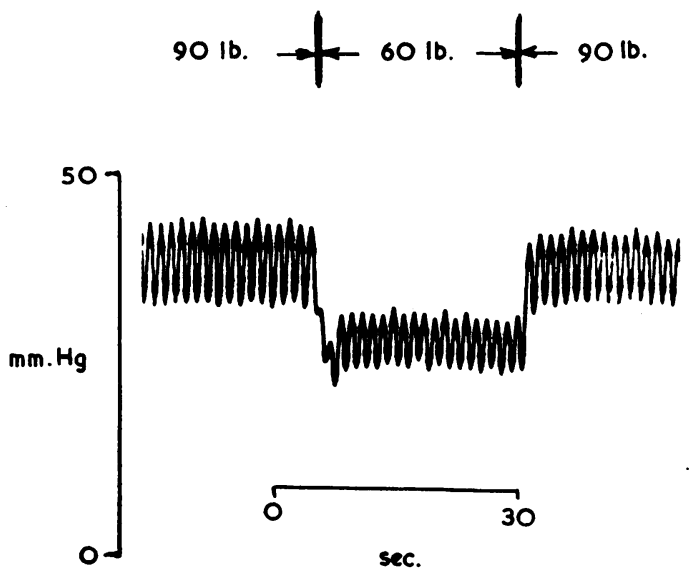

FIG. 4.-Arterial blood pressure during massage. Effect of different thrusts. the systolic pressure, it did have considerable control over the diastolic pressure. The faster the rate, the higher the diastolic pressure and so the smaller the pulse pressure (Fig. 5).

The rate of compression that gave the best pressure was between 60 and 70 a minute. When it fell below 30 a minute there was a significant fall in pressure.

High rates, e.g. 120 a minute, did not raise the pressure further. This is surprising for the dog's normal rate beat is of this order. This finding agrees with Weiser, Adler, and Kuhn (1962), who found 60 a minute the best rate of compression.

Thrust. The maximum blood pressure was obtained with a thrust of $90 \mathrm{lb}$. (41 kg.) This figure agrees with that of other workers (Harkins and Bramson, 1961; Nachlas and Siedband, 1962). Fig. 4 shows the effect on the blood pressure of different thrusts. 


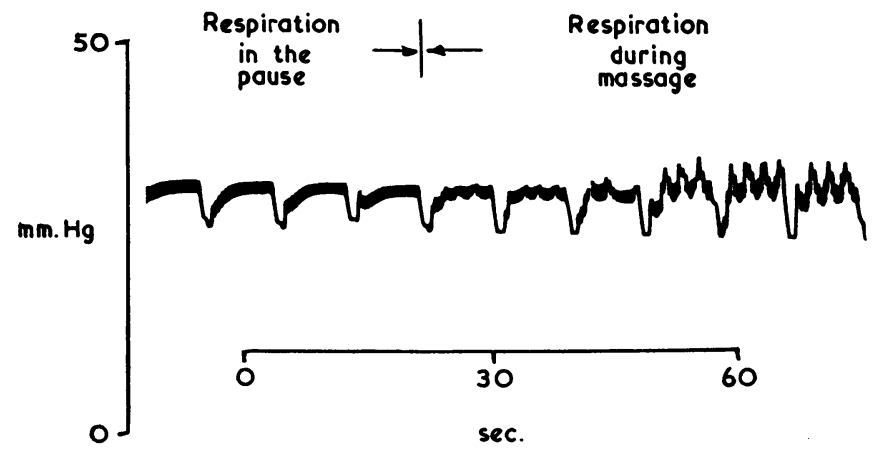

Fig. 5.-Arterial blood pressure during massage. 120 thrust/minute. Note small pulse pressure due to high rate of compression, and effect of respiration.

The Pause. We felt it advisable to inflate the lungs during a pause in the massage rather than on each upstroke or regardless of the massage. During the pause the pressure falls from the diastolic level but it does not reach zero unless the pause is extremely long. The ideal length of the pause was two seconds for this was just long enough to inflate the lungs fully; deflation was produced by the next compression.

The persistence of an arterial blood pressure during the pause is very important, for it will be seen later that at this time the venous pressure falls to zero.

During a two-second pause the pressure dropped by $2-15 \mathrm{~mm}$. $\mathrm{Hg}$ (see Fig. 3). Pauses longer than five seconds caused a falling off of the pressure obtained on recompression.

Inflation of the lungs during compression produced the same type of pressure fluctuation as normal respiration (Fig. 5). Inflation during the pause sometimes caused a rise in arterial pressure of 2-5 mm. Hg.

Manual Compression. Using manual compression we were able to produce higher pressures,

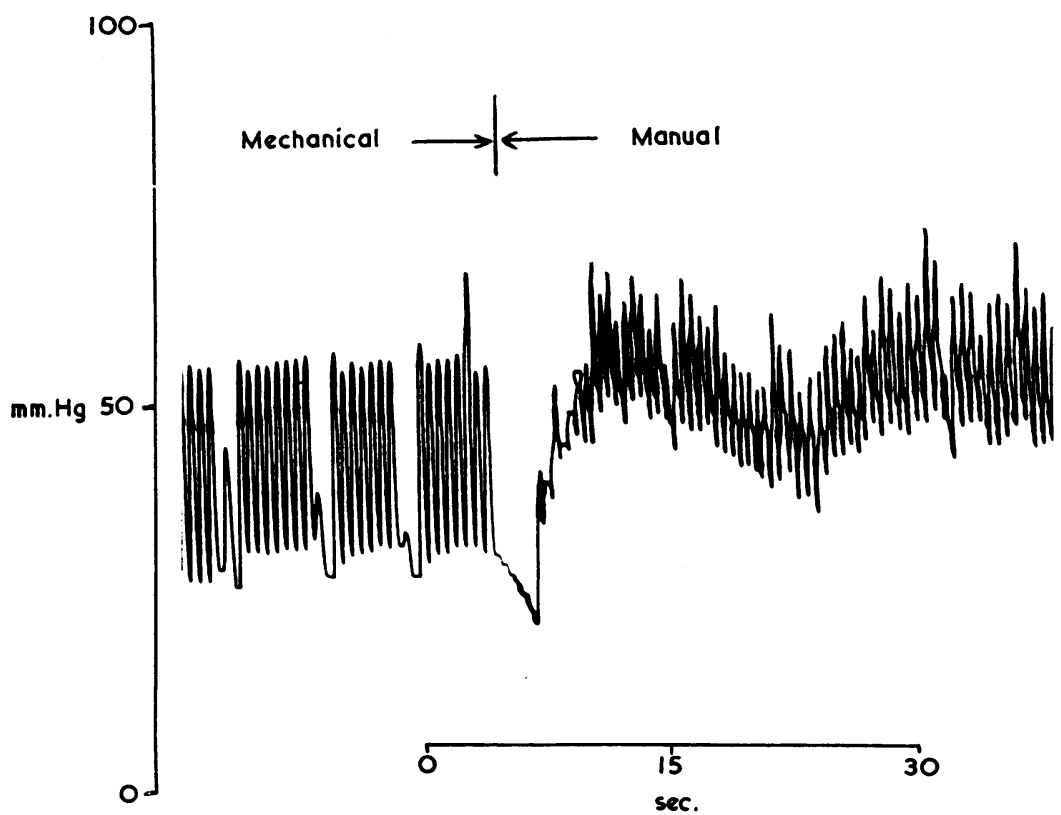

Fig. 6.-Arterial blood pressure. Comparison of mechanical and manual compression. 

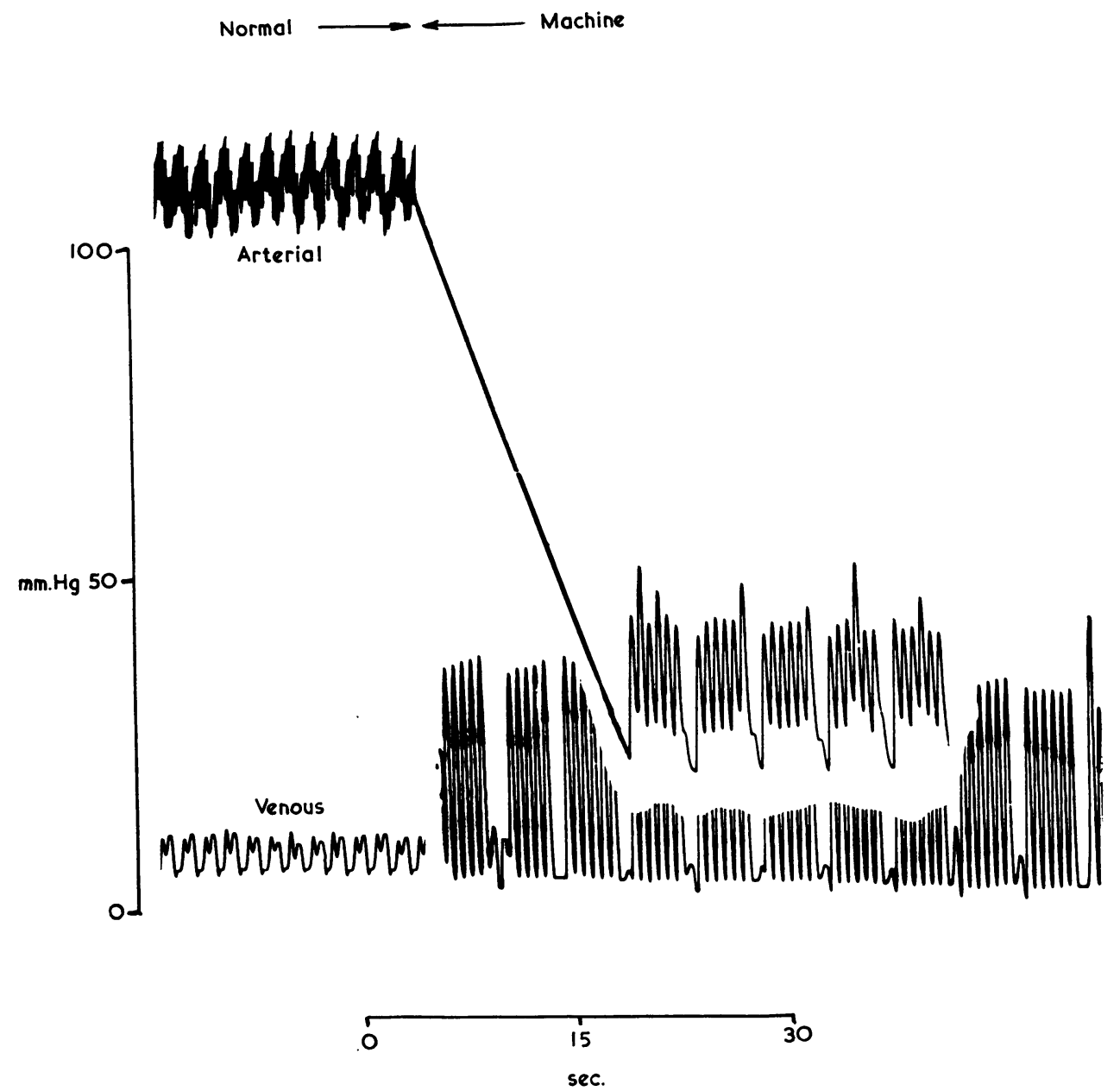

FIG. 7.-Arterial and venous blood pressures. Normal and with the cardiac massage unit. Note the change in $\mathrm{A}-\mathrm{V}$ pressure difference and the high venous pressure.

75-65 mm. Hg systolic, but it was impossible to apply a constant thrust and so the pressure was very irregular (Fig. 6).

The Venous Blood Pressure. We found, as reported by Weale and Rothwell-Jackson (1962), that the venous pressure during massage was very high. In the thoracic vena cava, the systolic venous pressure equalled the arterial pressure. In the abdominal vena cava, it was usually $20 \mathrm{~mm}$. $\mathrm{Hg}$ lower than the arterial pressure, and in the femoral vein it was lower still but nevertheless abnormally high.

Fig. 7 is a trace of the normal arterial and venous pressures, followed by the pressures recorded in the abdominal vena cava and the iliac artery during massage. The venous pressure is high in the dog during massage because external compression squashes not only the ventricles but the atria and great veins as well: it is important to note that it falls to zero between each compression and during the pause. In a few dogs we recorded negative pressures between compressions, presumably caused by the elastic recoil of the chest wall. This difference in the arterial and venous pressure curves means that there is an A-V pressure difference throughout "diastole" and during the pause. Flow can occur at this time, but there is unlikely to be any flow during compression, for the upstroke of the arterial and venous pressure curves is identical. 
TABLE I

Changes of Arterial and Venous Oxygen Saturation in Normal Dogs After Death

\begin{tabular}{|c|c|c|c|c|c|c|c|c|}
\hline & \multicolumn{4}{|c|}{ Control 1} & \multicolumn{4}{|c|}{ Control 2} \\
\hline & \multicolumn{4}{|c|}{$\begin{array}{l}\text { Time before and after death } \\
\text { (min.) }\end{array}$} & \multicolumn{4}{|c|}{$\begin{array}{l}\text { Time before and after death } \\
\text { (min.) }\end{array}$} \\
\hline & -5 & 5 & 12 & 20 & -5 & 5 & 12 & 20 \\
\hline $\begin{array}{l}\text { Arterial } \mathrm{O}_{2} \text { saturation }(\%) \\
\text { Venous } \mathrm{O}_{2} \text { saturation (\%) }\end{array}$ & $\begin{array}{l}96 \\
75\end{array}$ & $\begin{array}{l}93 \\
85\end{array}$ & $\begin{array}{l}50 \\
78\end{array}$ & $\begin{array}{l}26 \\
67\end{array}$ & $\begin{array}{l}97 \\
85\end{array}$ & $\begin{array}{l}84 \\
47\end{array}$ & $\begin{array}{l}80 \\
55\end{array}$ & $\begin{array}{l}71 \\
51\end{array}$ \\
\hline
\end{tabular}

TABLE II

Changes of Arterial and Venous Oxygen Saturation during Mechanical Cardiac Compression

\begin{tabular}{|c|c|c|c|c|c|c|c|}
\hline & & \multirow[t]{2}{*}{$\begin{array}{l}\text { Experiment } \\
\text { No. }\end{array}$} & \multirow[t]{2}{*}{$\begin{array}{l}\text { Before } \\
\text { massage }\end{array}$} & \multicolumn{4}{|c|}{$\begin{array}{l}\text { Time (min.) } \\
\text { after beginning massage }\end{array}$} \\
\hline & & & & 5 & 10 & 15 & 20 \\
\hline Arterial $\mathrm{O}_{2}$ saturation $(\%)$ & .. & $\begin{array}{l}1 \\
2\end{array}$ & $\begin{array}{l}95 \\
96\end{array}$ & 100 & $\underline{98}$ & $\begin{array}{l}97 \\
99\end{array}$ & $\underline{97}$ \\
\hline Venous $\mathrm{O}_{2}$ saturation $(\%)$ & .. & $\begin{array}{l}3 \\
4 \\
2\end{array}$ & $\begin{array}{l}72 \\
86 \\
75\end{array}$ & $\begin{array}{l}15 \\
52 \\
-\end{array}$ & $\begin{array}{l}16 \\
26 \\
-\end{array}$ & $\begin{array}{l}23 \\
24 \\
33\end{array}$ & $\begin{array}{l}30 \\
17 \\
-\end{array}$ \\
\hline
\end{tabular}

Circulation Times. Circulation times were measured in four dogs: all had a systolic arterial blood pressure of approximately $55 \mathrm{~mm}$. $\mathrm{Hg}$. The rate of compression was 60 a minute, and the pause of 2 seconds occurred after every fifth compression. The circulation time between the right femoral vein and the left femoral artery was $90,35,45$, and 40 seconds: the normal circulation time is $7-8$ seconds.

Attempts to measure cardiac output failed because the curves obtained were too flat to allow accurate calculation. A curve was obtained and this confirms that circulation was present: the dye first appeared at 15 seconds and concentration was maximal at 40 seconds.

All of these figures show that the massage was producing a circulation 5 to 10 times slower than normal.

Artificial Respiration. As the respiratory movements produced by chest compression during massage are probably insufficient for gas exchange (Safar et al., 1961), a pause was necessary to allow lung inflation. In these experiments the lungs were inflated manually with oxygen via an endotracheal tube because the machine was not fitted with the automatic lung inflation valve.

Blood Oxygen Saturation. When attempts to measure cardiac output failed, we decided to make serial measurement of the arterial and venous oxygen saturation believing that changes in oxygen levels would indicate the presence or absence of a circulation and also indicate whether the circulation, pulmonary and systemic, and the artificial respiration were adequate for the oxygen requirements of the animal.

Two animals were used as controls (Table I). Arrest was produced with potassium, and they were respired in the usual way. After death the arterial (aorta) oxygen saturation fell quickly: to below 50 per cent in one, and to 70 per cent in the other, within 20 minutes. The venous (vena cava) oxygen remained unchanged in one and dropped in the other. In 4 animals undergoing mechanical massage, the arterial oxygen remained high while the venous oxygen dropped to very low levels (Table II). 
We consider these results indicate an adequate degree of oxygenation in the pulmonary circulation and confirm that the systemic circulation is very slow.

Trauma. The first two animals had small tears in the liver with hæmoperitoneum. Strapping the abdomen prevented this. Rupture of the liver does not seem to be due to direct trauma, provided the compression is applied in the correct place, but to the shearing strain as it is pushed rapidly up and down in the abdomen. No ribs were fractured, but all had a little sub-pleural bruising. The lungs, heart, and great vessels were all normal.

\section{SURVIVAL EXPERIMENTS}

A dog weighing $11 \mathrm{~kg}$. was anæsthetized with pentobarbitone sodium; cardiac arrest was produced with $30 \mathrm{mEq}$ potassium chloride. Massage was begun after one minute of complete arrest; 60 thrusts a minute, $90 \mathrm{lb}$. thrust, 2-second pause after every fifth beat. The lungs were inflated with oxygen in each pause. An arterial blood pressure of $60 / 40 \mathrm{~mm} . \mathrm{Hg}$ and a venous pressure (abdominal vena cava) of $40 / 5 \mathrm{~mm}$. $\mathrm{Hg}$ were obtained. After 30 minutes of massage the arterial blood pressure began to rise and the heart started to beat normally. The animal was awake two hours later and made a full recovery. Five days later it was sacrificed. There were three broken ribs; the histology of the heart, liver, and kidneys was normal, but there was a little interstitial œdema in the lungs.

\section{DISCUSSION}

We have shown that an automatic device is capable of maintaining a blood pressure and blood flow equal to that reported to be produced by manual methods in dogs. Almost all of the experimental work on external cardiac massage has been done with dogs, and there are very few data, apart from some pressure recordings, in man. Although it would be misleading to transfer any quantitative conclusions about the one animal to the other, most workers have thought it reasonable to transfer principles. This has been justified in practice, for what has worked in the dog has worked in man and, in fact, the quantitative effects have been better. We therefore feel justified in suggesting that not only will the cardiac massage unit work in man but it will probably produce better pressures and flows than it does in dogs.

This paper does not intend to enter into the argument on the relative efficacy of internal or external massage. It does, however, lend support to those who favour external massage for it shows that in spite of the associated high venous pressures, which the protagonists of internal massage deplore, blood flow does occur. We can find no published recordings of central venous pressure during human external massage, but we suspect, because of the anatomy of the thoracic cage, pericardium, and heart, that it does not rise to the same heights as in the dog. There is no doubt that, in the dog, external massage compresses the whole of the thoracic contents, but it seems that in man the ventricles are compressed more than any other part of the heart or the great veins.

The practical advantages of the cardiac massage unit are considerable. It is portable, easily applied, reliable, with automatic and simple controls. That it works in human beings will we hope be the subject of a future communication. We have tried it on recently dead subjects and found that it gives a good pulse, without damaging the chest.

\section{SUMMARY}

A simple portable pneumatic device for automatic external cardiac massage is described. It is capable of producing an arterial blood pressure between 80 and $40 \mathrm{~mm}$. $\mathrm{Hg}$ and a systemic blood flow sufficient to maintain life in dogs. Its rate and thrust are infinitely variable, and artificial respiration can be given in a pause during massage.

It is suggested that this is a safer, more reliable, and more efficacious way of applying external cardiac compression than manual massage. 
We thank the Research Committee of the North West Regional Metropolitan Hospital Board for a grant to Dr. Keating to enable the first machine to be constructed, and Shipston Engineering Co. Ltd., Shipston-on-Stour, Warwickshire, for subsequent assistance.

The machine is protected under British Patent No. 24156/62.

We are indebted to Dr. P. Cliffe and to the Department of Clinical Measurement, Westminster Hospital, for the blood oxygen measurements and the dye dilution studies.

We thank the Department of Medical Photography, Westminster Hospital for Fig. 1 and 2.

\section{REFERENCES}

Birch, L. H., Kenney, L. J., Doornbos, F., Kosht, D. W., and Barkalow, C. E. (1962). A study of external cardiac compression. J. Mich. med. Soc., 61, 1346.

Harkins, G. A., and Bramson, M. L. (1961). Mechanized external cardiac massage for cardiac arrest and for support of the failing heart. J. surg. Res., $1,197$.

Nachlas, M. M., and Siedband, M. P. (1962). A simple portable pneumatic pump for external cardiac massage. Amer. J. Cardiol., 10, 107.

Safar, P., Brown, T. C., Holtey, W. J., and Wilder, R. J. (1961). Ventilation and circulation with closed chest cardiac massage in man. J. Amer. med. Ass., 176, 574.

Weale, F. E., and Rothwell-Jackson, R. L. (1962). The efficiency of cardiac massage. Lancet, 1, 990.

Weiser, F. M., Adler, L. N., and Kuhn, L. A. (1962). Hemodynamic effects of closed and open chest cardiac resuscitation in normal dogs and those with acute myocardial infarction. Amer. J. Cardiol., $10,555$. 